\title{
Effect of Calcium Carbonate Incorporation on the Properties of Low Linear Density Polyethylene/Thermoplastic Starch Blends
}

\author{
Amirah Hulwani Mohd Zain ${ }^{1}$, Mohamad Kahar bin Ab Wahab ${ }^{1 *}$ and \\ Hanafi Ismail ${ }^{2}$
${ }^{1}$ School of Materials Engineering, Universiti Malaysia Perlis, 02600 Arau, Perlis, Malaysia
${ }^{2}$ School of Materials and Mineral Resources Engineering,
Universiti Sains Malaysia, Engineering Campus, 14300 Nibong Tebal, Pulau Pinang, Malaysia
"Corresponding author: kaharwahab@unimap.edu.my

Published online: 31 December 2019

To cite this article: Amirah Hulwani Mohd Zain, Mohamad Kahar bin Ab Wahab and Hanafi Ismail (2019). Effect of calcium carbonate incorporation on the properties of low linear density polyethylene/thermoplastic starch blends. Journal of Engineering Science, 15(2), 97-108, https://doi.org/10.21315/jes2019.15.2.7.

To link to this article: https://doi.org/10.21315/jes2019.15.2.7

\begin{abstract}
The characterisation of low linear density polyethylene/thermoplastic starch (LLDPE/TPS) composite with calcium carbonate ( $\mathrm{CaCO}_{3}$ ) filler was investigated. LLDPE/ TPS composite with different $\mathrm{CaCO}_{3}$ loadings were prepared using HAAKE internal mixer at $145^{\circ} \mathrm{C}$ and rotor speed of $50 \mathrm{rpm}$. The first step includes the preparation of TPS using heated two roll mill at temperature of $150^{\circ} \mathrm{C}$. All composites were characterised by Instron machine, scanning electron microscopy (SEM), thermogravimetry analysis (TGA), and Fourier transform infrared (FTIR) spectroscopy. The result indicated that LLDPE/TPS blends with incorporation of $\mathrm{CaCO}_{3}$ gave higher value of tensile properties as compared to LLDPE/TPS blend. However, at higher $\mathrm{CaCO}_{3}(30 \%)$ loading, the particles tend to form the agglomeration within the matrix. The agglomeration formation decreases the mechanical properties of LLDPE/TPS composite by weakening the interfacial interaction between the matrix and the filler particle as shown in morphological study. The incorporation of $\mathrm{CaCO}_{3}$ particles also improve the thermal stability of LLDPE/TPS blends as shown in thermogravimetric curve.
\end{abstract}

Keywords: LLDPE, thermoplastic starch, $\mathrm{CaCO}_{3}$, mechanical properties, thermal properties 


\section{INTRODUCTION}

Interest in bio-degradable polymers has continued to increase due to the problems associated with the plastics disposal and effects on the environment. Biodegradable plastic is a plastic designed to undergo a significant change in its chemical structure under specific environmental condition, resulting in a loss of some properties. The change in chemical structure are result from the action of naturally occurring microorganism. Starch are widely used as a viable alternative to making biodegradable plastic. Starch is cheap, renewable, and biodegradable, but it lacks in strength, low water resistance, and processability. To improve the targeted properties, starch is often blended with other biodegradable polymers such as poly ( $\varepsilon$-caprolactone) (PCL), polylactic acid (PLA), and polyvinyl alcohol (PVA), ${ }^{1-5}$ or with conventional petroleum-based plastic, such as polyethylene (PE) and polypropylene (PP). ${ }^{6-11} \mathrm{PE}$ is regarded as an inert bulk polymer and slowly degradable compared to PLA and PVA, in which PE takes longer time to degrade. ${ }^{12-14}$ On the other hand, lack in mechanical properties and weak moisture resistance of starch can be overcome by blending it with low linear density polyethylene (LLDPE), which has high strength, flexible, and high mechanical properties. Starches are incorporated during producing plastic films, will enhance the accessibility of the PE plastic to oxygen and microorganism attack and leads to chain breakdown. Thermoplastic starch (TPS) as opposed to native starch, which is capable to flow and can be processed with conventional plastic equipment. ${ }^{15}$ TPS is obtained from plasticised starch, in the presence of glycerol as the plasticiser. TPS has been melt blended with synthetic polymers to produce partially biodegradable materials, which shows high ductility similar to certain commercial plastics. ${ }^{16} \mathrm{In}$ this study, calcium carbonate $\left(\mathrm{CaCO}_{3}\right)$ was used as reinforcing filler in LLDPE/ TPS matrix to compensate the deterioration of blends properties due to the presence of TPS. The effect of $\mathrm{CaCO}_{3}$ as reinforcing filler on the mechanical, morphology, and thermal properties were focused in this study.

\section{EXPERIMENTAL}

\subsection{Materials}

LLDPE was purchased from Lotte Chemical Titan (Johor, Malaysia) with density of $0.920 \mathrm{~g} \mathrm{~cm}^{-3}$. Food grade cassava starch was used to prepare TPS. $\mathrm{CaCO}_{3}$ in odourless and fine white powder was purchased from Sigma Aldrich Chemical Company (St Louis, Missouri, USA) with density of $2.83 \mathrm{~g} \mathrm{~cm}^{-3}$. Glycerol used as plasticiser was also supplied by Sigma Aldrich Chemical Company (St. Louis, Missouri, USA). 


\subsection{LLDPE/TPS/CaCO 3 Composites Preparation}

TPS was prepared using $65 \%$ of cassava starch and premixed with $35 \%$ of glycerol. ${ }^{17}$ The mixtures were stored in room temperature for $24 \mathrm{~h}$ after the preparation. This is to allow the plasticiser to permeate inside the starch granule. Then, the mixtures were mixed by using hot two roll mill at temperature of $150^{\circ} \mathrm{C}$ for $10 \mathrm{~min}$. For LLDPE/TPS/CaCO${ }_{3}$ composites, the LLDPE/TPS matrix were compounded with different $\mathrm{CaCO}_{3}$ loadings, which varied from $5 \%$ to $30 \%$. The compounding process was done using HAAKE internal mixer (Thermo Fischer Scientific, Massachusetts, USA) at temperature of $135^{\circ} \mathrm{C}$ for $15 \mathrm{~min}$. Then, the compounding was moulded into $1 \mathrm{~mm}$ sheets using a hot press machine.

\section{CHARACTERISATION}

\subsection{Tensile Testing}

Instron Tensile Test Machine 3366 was used to analyse the mechanical properties of the blends. The specimens were cut into a rectangular shape, with the dimension of $100 \mathrm{~mm}$ total length, $50 \mathrm{~mm}$ gauge length, $30 \mathrm{~mm}$ width, and $1 \mathrm{~mm}$ thickness for the tensile test under ISO 527-3. ${ }^{17}$ The cross-head speed was set at $50 \mathrm{~mm} \mathrm{~min}{ }^{-1}$ under an ambient temperature. An average value was taken out of five samples to get an accurate value of tensile strength, modulus of elasticity, and elongation at break.

\subsection{Morphology Study}

The morphological studies were carried out on the tensile fracture surface using the analytical scanning electron microscopy (SEM) (model JEOL JSM$6460 \mathrm{LA}$, Tokyo, Japan) with the supply of accelerating voltage at $10 \mathrm{kV}$. The tensile fracture sample was coated with palladium layer at about $1.5-3.0 \mathrm{~nm}$ thickness with aid of utilising the auto fine coater (model JEOL JFC 1600, Tokyo, Japan) to prevent the charging effect on the surface morphology.

\subsection{Structural Analysis}

Fourier transform infrared spectroscopy (FTIR) (model Perkin Elmer spectrometer 2000, Massachusetts, USA) was used to inspect structural changes at a resolution of $4 \mathrm{~cm}^{-1}$ and in the range of $4,000-650 \mathrm{~cm}^{-1}$. The samples were scanned for 32 times for a good resolution on the reading. 


\subsection{Thermal Stability}

The thermogravimetric analysis (TGA) (model Pyris Diamond, PerkinElmer, Massachusetts, USA) was used to measure the amount and rate of change in weight of material as function of temperature and time in a controlled atmosphere. The sample was heated from the $20^{\circ} \mathrm{C}$ to $700^{\circ} \mathrm{C}$ at $10^{\circ} \mathrm{C} \mathrm{min}{ }^{-1}$ under nitrogen atmosphere.

\section{RESULTS AND DISCUSSION}

\subsection{Tensile Properties of LLDPE/TPS Blends}

Effect of TPS content towards properties of LLDPE has been identified by blending both materials at different TPS loadings. Blending of TPS with LLDPE affect the properties of the LLDPE, which it tends to reduce the tensile properties. Based on Figures 1 and 2, the tensile strength of LLDPE/TPS decrease with increase of TPS content. The tensile strength of the LLDPE, which was $20.1 \mathrm{MPa}$ decreased as the TPS loading increased until $4.9 \mathrm{MPa}$ at 50 wt. \%. However, to optimise the biodegradable properties, LLDPE/TPS with blend ratio of 70:30 was chosen due to acceptable tensile properties than other compositions. The tensile strength for LLDPE/TPS (70/30) was $7.9 \mathrm{MPa}$ with $467 \%$ of elongation at break value. In Figure 3, the tensile strength of LLDPE/TPS blend improved as $\mathrm{CaCO}_{3}$ was initially added. The tensile strength increased from 7.9 to $12.1 \mathrm{MPa}$ at $5 \%$

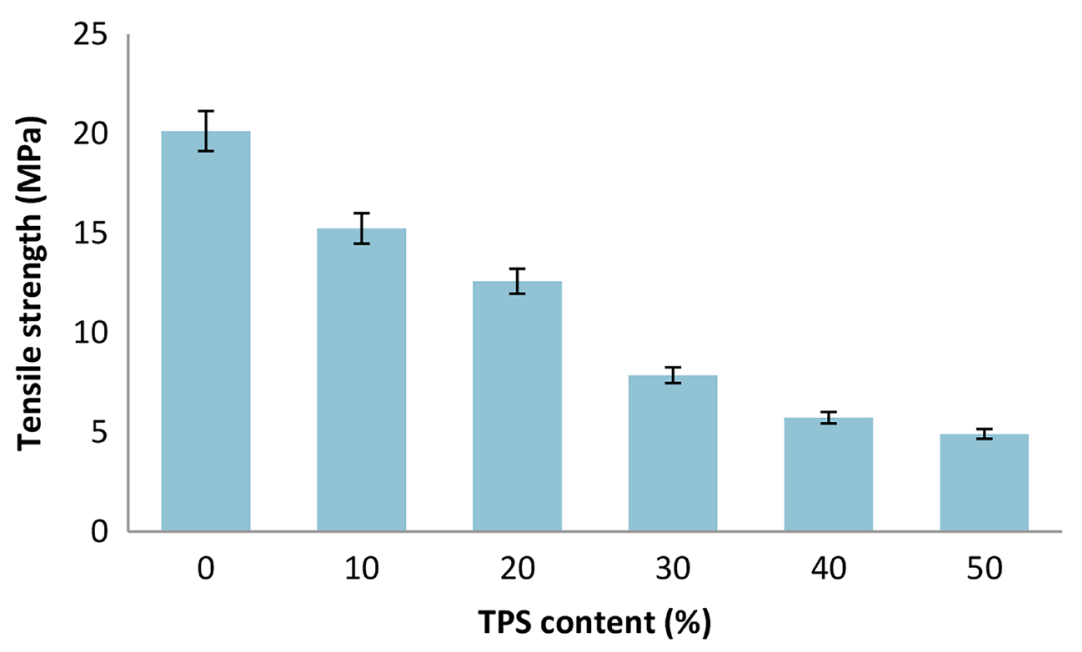

Figure 1: Effect of TPS content on tensile strength of LLDPE/TPS blend. 
filler loading. The initial increase in strength of the composite is due to good fillermatrix interaction. ${ }^{18}$ It enables more stress to be transferred from the matrix to the filler when external forces is applied. However, further increase in $\mathrm{CaCO}_{3}$ loading will influence the tensile strength value. The decrement in tensile strength value at $20 \%$ and $30 \%$ TPS loading was attributed to the formation of filler aggregates. The aggregates are easily detached from the LLDPE/TPS matrix and resulted in decrease of the strength of the composite.

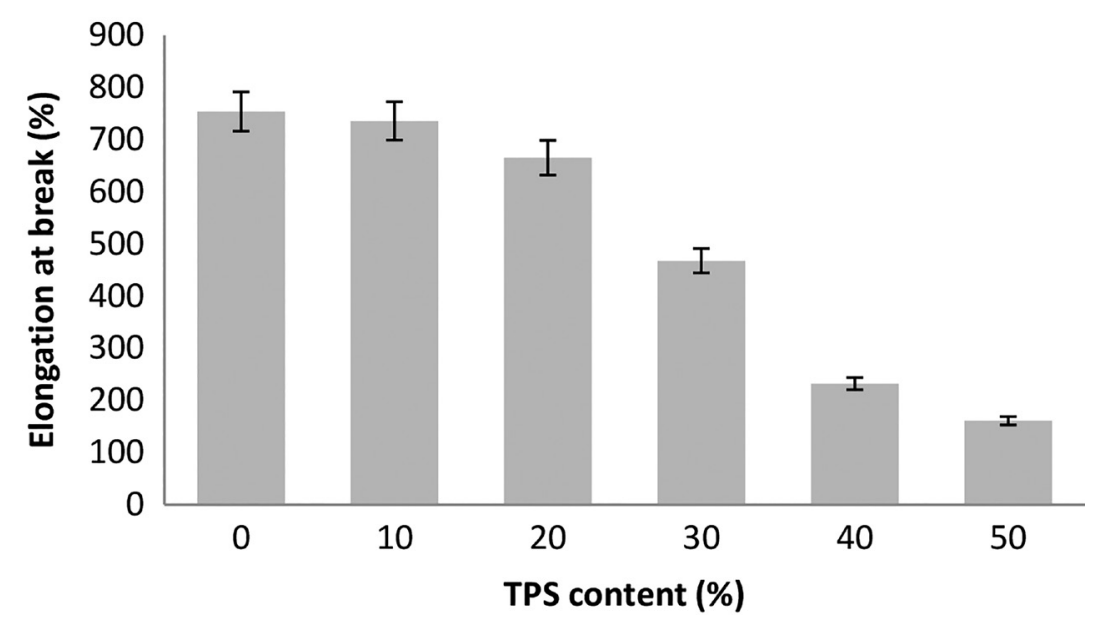

Figure 2: Effect of TPS content on elongation at break (\%) of LLDPE/TPS blend.

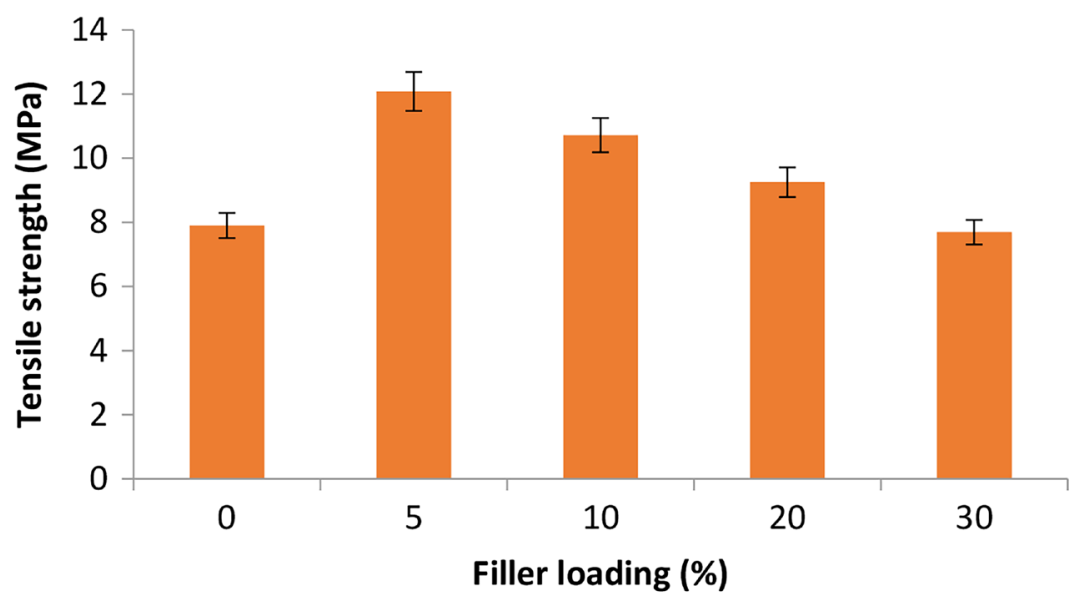

Figure 3: Effect of filler loading on tensile strength of LLDPE/TPS blend. 


\subsection{SEM Morphology of LLDPE/TPS and LLDPE/TPS/ $\mathrm{CaCO}_{3}$ Composites}

To study the interfacial adhesion between the matrix and the dispersed phase, SEM micrographs of fracture surface were observed at $300 \times$ magnification (as shown in Figure 4). Based on Figure 4(a), SEM micrograph at 10\% of TPS loading shown that the blend exhibited smooth fracture surface compared to another blend. SEM micrograph for TPS- $40 \%$ gave rougher surface than SEM micrograph TPS-30\% (as shown in Figures 4[c] and [d]), which it clearly showed less homogeneity and interfacial adhesion. The starch particles were completely disrupted and some of them were pull-out from the surface of the blend, thus, leaving several cavities in the fracture surface. Immiscibility of TPS effect the mechanical properties of the blending, which it decreased tensile properties. However, it gives better degradability characteristic on the blends. The increase in TPS content will increase the surface areas for the microbes to consume, and thus create pores on the LLDPE/TPS surface. Effects of $\mathrm{CaCO}_{3}$ loading on the LLDPE/TPS matrix can be observed from the SEM micrographs (as shown in Figure 5). Figure 5(a) show good dispersion of $\mathrm{CaCO}_{3}$ in the LLDPE/TPS matrix. With increase of $\mathrm{CaCO}_{3}$, the particle tends to attract each other and group together forming the agglomerations. Besides, the detachment of $\mathrm{CaCO}_{3}$ from LLDPE/TPS matrix causes voids, which can lead to the crack formation in the blends.

\subsection{Structural Analysis}

Based on Figure 6, there were two characteristic peaks of LLDPE between 2,915 and $2,846 \mathrm{~cm}^{-1}$, which attributed to $\mathrm{C}-\mathrm{H}$ stretch of alkanes. The peaks at 1,467 and $717 \mathrm{~cm}^{-1}$ were attributed to $\mathrm{C}-\mathrm{H}_{2}$ bending ${ }^{19}$ and two peaks from 1,151 and $1,020 \mathrm{~cm}^{-1}$ were attributed to $\mathrm{C}-\mathrm{O}-\mathrm{C}$ bond bending while peak at $3,245 \mathrm{~cm}^{-1}$ attributed to $\mathrm{O}-\mathrm{H}$ bond stretching, which it characterise TPS functional group. ${ }^{20}$ In addition, the characterisation peaks for $\mathrm{O}-\mathrm{H}$ bond and $\mathrm{C}-\mathrm{O}-\mathrm{C}$ bond show obvious spectrum peaks, indicating the possible interaction of the starch with glycerol. The presence of $\mathrm{CaCO}_{3}$ was identified by the existence of $\mathrm{O}-\mathrm{C}-\mathrm{O}$ bond in LLDPE/TPS composite. Spectrum peaks of 927 and $926 \mathrm{~cm}^{-1}$ for LLDPE/TPS$10 \% \mathrm{CaCO}_{3}$ and LLDPE/TPS-30\% $\mathrm{CaCO}_{3}$, respectively, attributed to $\mathrm{O}-\mathrm{C}-\mathrm{O}$ bending band. Band spectrum for $\mathrm{O}-\mathrm{C}-\mathrm{O}$ at $926 \mathrm{~cm}^{-1}$ is wider than band spectrum at $927 \mathrm{~cm}^{-1}$ due to the amount of $\mathrm{CaCO}_{3}$ used in LLDPE/TPS matrix. 

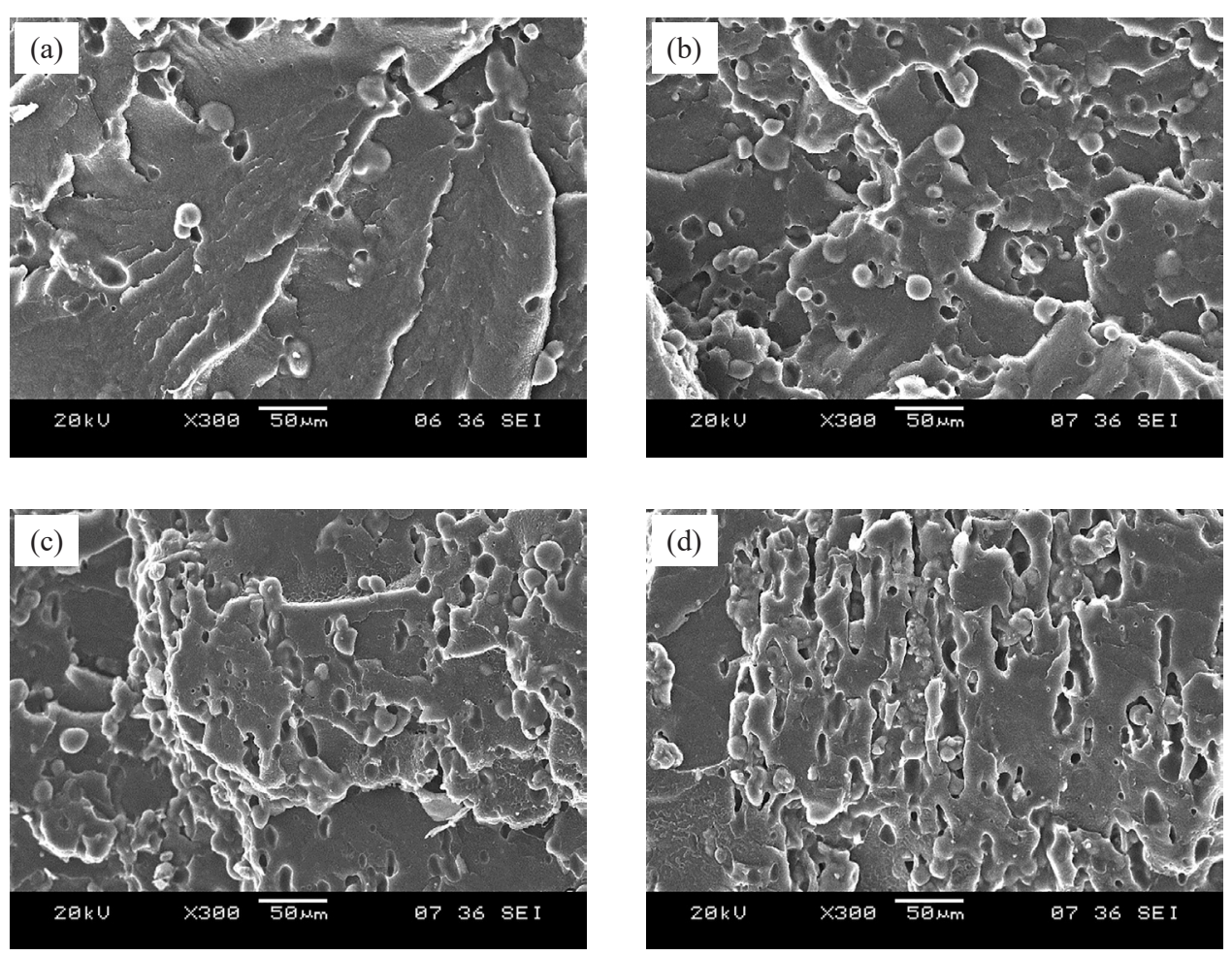

Figure 4: SEM micrograph for LLDPE/TPS blend: (a) TPS-10\%, (b) TPS-20\%, (c) TPS-30\%, and (d) TPS- $40 \%$ at $300 \times$ magnification.
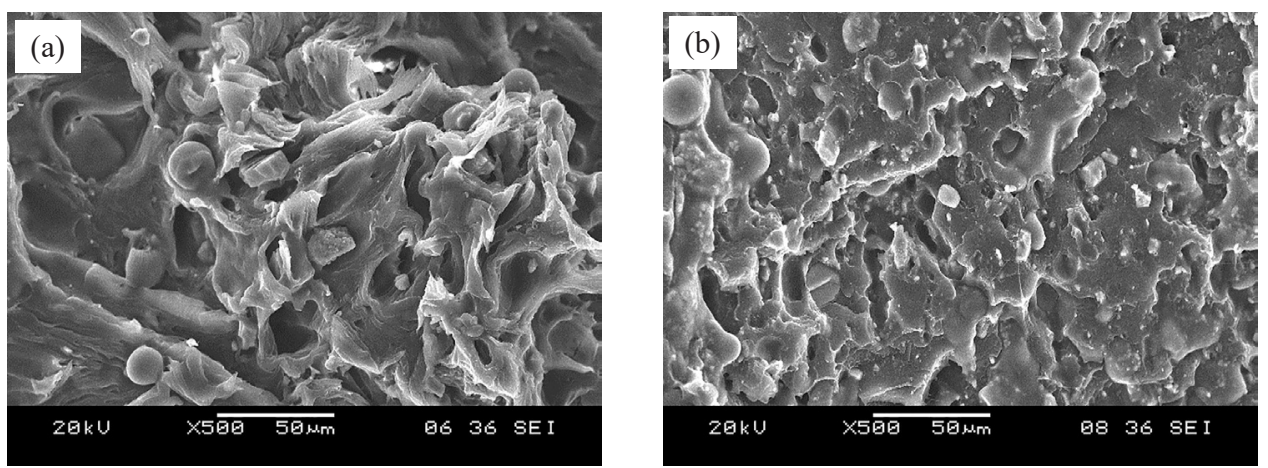

Figure 5: SEM micrograph of LLDPE/TPS blend: (a) LLDPE/TPS-10\% $\mathrm{CaCO}_{3}$ and (b) $\mathrm{LLDPE} / \mathrm{TPS}-30 \% \mathrm{CaCO}_{3}$ at $500 \times$ magnification. 


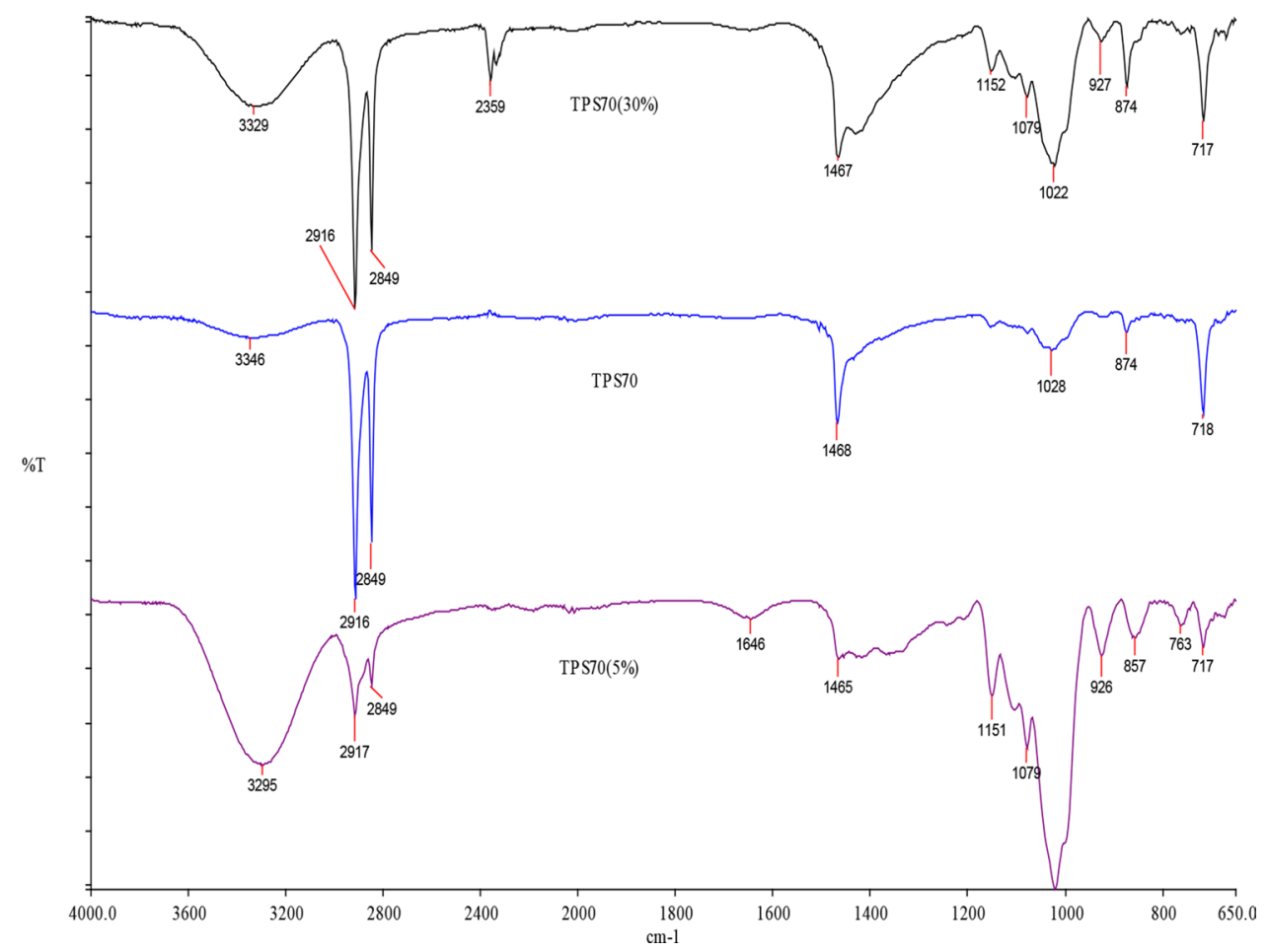

Figure 6: FTIR spectrum of LLDPE/TPS, LLDPE/TPS- $10 \% \mathrm{CaCO}_{3}$, and LLDPE/ TPS-30\% $\mathrm{CaCO}_{3}$ composites.

\subsection{Thermal Stability of LLDPE/TPS/CaCCO${ }_{3}$ Composites}

Figure 7 shows the TGA thermogram for LLDPE/TPS composite at different $\mathrm{CaCO}_{3}$ loadings. TG curves for all compounds exhibit three stages of decomposition. First stage of decomposition start at temperature between $90^{\circ} \mathrm{C}$ to $200^{\circ} \mathrm{C}$, which involve the evaporation and elimination of water and glycerol in the TPS phase..$^{21}$ The second stage, at temperature between $250{ }^{\circ} \mathrm{C}$ to $350^{\circ} \mathrm{C}$, is attributed to decomposition of TPS in the composite. ${ }^{22}$ The last stage, ranging from $380^{\circ} \mathrm{C}$ to $480^{\circ} \mathrm{C}$ is attributed to LLDPE decomposition curve..$^{23}$ The remaining weight above the $500^{\circ} \mathrm{C}$ is attributed to $\mathrm{CaCO}_{3}$ because the decomposition temperature for $\mathrm{CaCO}_{3}$ is between $850^{\circ} \mathrm{C}-900^{\circ} \mathrm{C} .{ }^{22} \mathrm{Besides}$ that, the decomposition temperatures curves of the blends increase to higher temperature showing increased stability when $\mathrm{CaCO}_{3}$ is added. 


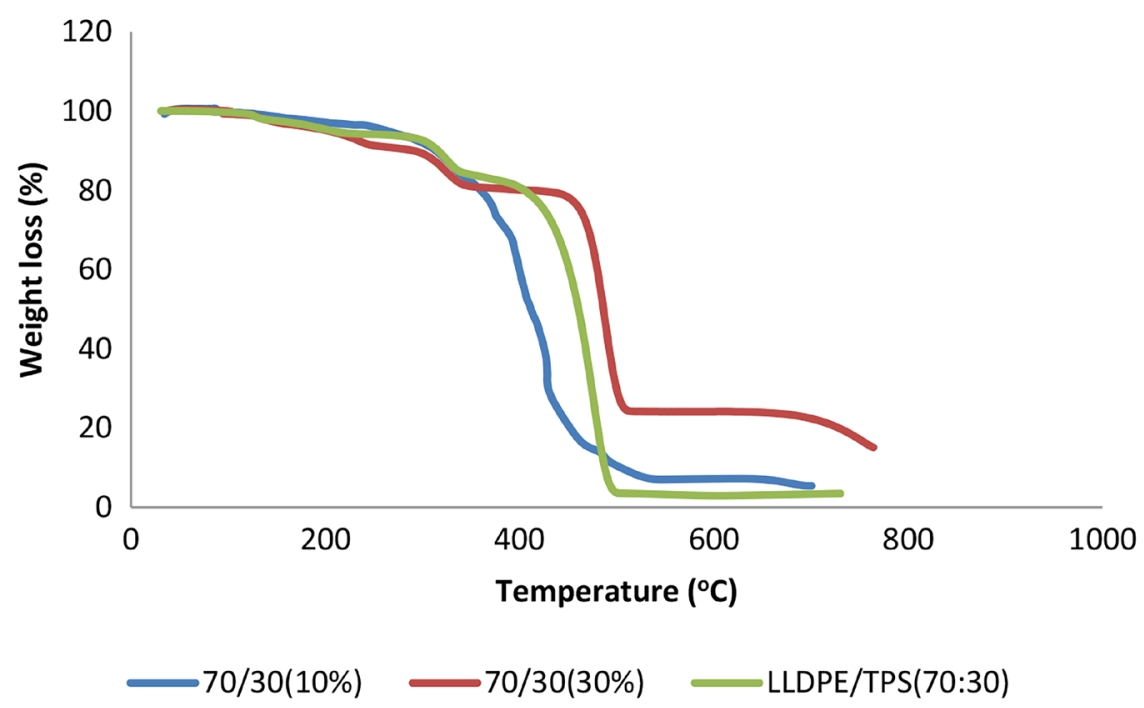

Figure 7: TGA thermograms of LLDPE/TPS, LLDPE/TPS-10\% $\mathrm{CaCO}_{3}$, and LLDPE/ TPS-30\% $\mathrm{CaCO}_{3}$ composites.

\section{CONCLUSION}

Optimum LLDPE/TPS blend chosen was 70/30 due to acceptable tensile properties along with partial biodegradable properties. From SEM micrograph, increased weight percentage of TPS tends to form agglomeration and reflect in reduction for tensile strength. In order to give better properties of LLDPE/TPS blend, addition of $\mathrm{CaCO}_{3}$ filler was performed at different weight percentages, ranging from $5 \%$ to $30 \%$. The tensile strength increased up to $12.0 \mathrm{MPa}$ for $10 \%$ $\mathrm{CaCO}_{3}$ loading and further $\mathrm{CaCO}_{3}$ incorporation tends to decrease the tensile value. Among the LLDPE/TPS composites, LLDPE/TPS composite at 70:30 composition with $10 \%$ of $\mathrm{CaCO}_{3}$ showed the best tensile strength and thermal stability.

\section{ACKNOWLEDGEMENTS}

The authors wish to gratefully acknowledge the School of Materials Engineering, as well as the Research and Innovation Department under Universiti Malaysia Perlis and Ministry of Higher Education (MOHE) Malaysia (Ref: FRGS/1/2019/TK05/UNIMAP/02/13) for supporting this research project. 


\section{REFERENCES}

1. Das, K., Ray, D., Bandyopadhyay, N. R., Gupta, A., Sengupta, S., Sahoo, S. \& Misra, M. (2010). Preparation and characterization of cross-linked starch/poly (vinyl alcohol) green films with low moisture absorption. Ind. Eng. Chem. Resear., 49(5), 2176-2185, https://doi.org/10.1021/ ie901092n.

2. Gadhave, R. V., Das, A., Mahanwar, P. A. \& Gadekar, P. T. (2018). Starch based bio-plastics: The future of sustainable packaging. Open J. Polym. Chem., 8(2), 21-33, https://doi.org/10.4236/ojpchem.2018.82003.

3. Ibrahim, N., Kahar, A. W. M. \& Ismail, H. (2017). Physical and degradation properties of polylactic acid and thermoplastic starch blends: Effect of citric acid treatment on starch structures. Bio-res., 12(2), 3076-3087, https://doi.org/10.15376/biores.12.2.3076-3087.

4. Ismail, N. A., Mohd Tahir, S., Yahya, N., Abdul Wahid, M. F., Khairuddin, N. E., Hashim, I., Rosli, N. \& Abdullah, M. A. (2016). Synthesis and characterization of biodegradable starch-based bioplastics. Mater. Sci. Forum, 846, 673-678, https://doi.org/10.4028/www.scientific.net/ MSF.846.673.

5. Zhu, F. (2015). Review: Composition, structure, physicochemical properties, and modifications of cassava starch. Carbohyd. Polym., 122, 456-480, https://doi.org/10.1016/j.carbpol.2014.10.063.

6. Kahar, A. W. M. \& Ismail, H. (2016). High density polyethylene/natural rubber blends filled with thermoplastic tapioca starch: Physical and isothermal crystallization kinetics study. J. Vinyl Add. Technol., 22(3), 191-199, https://doi.org/10.1002/vnl.21422.

7. Samson, O. A., Mohammed, A. U., Emmanuel, I. A. \& Winifred, I. D. (2014). Characterization of LDPE reinforced with calcium carbonate: Fly ash hybrid filler. J. Miner. Mater. Charac. Eng., 2(4), 334-345, https://doi.org/10.4236/jmmce.2014.24038.

8. Azizan, A., Dahlan, H. M. \& Ibrahim, A. (2003). Mechanical properties of filled NR/LLDPE blends. Ira. Polym. J., 13(3), 173-178.

9. Kaseem, M., Hamad, K. \& Deri, F. (2012). Thermoplastic starch blends: A review of recent works. Polym. Sci. Series A, 54(2), 165-176, https://doi.org/10.1134/S0965545X1202006X.

10. Barczewski, M., Lewandowski, K., Schmidt, M. \& Szostak, M. (2016). Melt fracture and rheology of linear low density polyethylene: Calcium carbonate composites. Polym. Eng. Sci., 57(9), 998-1004, https://doi. org/10.1002/pen.24477. 
11. Mustafa, A. G., Azman, H. \& Abdirahman, Y. (2011). Mechanical and thermal properties of calcium carbonate-filled PP/LLDPE composite. J. App. Polym. Sci., 121(4), 2413-2421, https://doi.org/10.1002/app.33570.

12. Kumar, P., Prakash, K. S., Jan, K., Swer, T. L., Jan, S., Verma, R., Deepika, K., Dar M. Z., Verma, K. \& Bashir, K. (2017). Effects of gamma irradiation on starch granule structure and physicochemical properties of brown rice starch. J. Cer. Sci., 77, 194-200, https://doi.org/10.1016/j. jcs.2017.08.017.

13. Kong, X. (2018). Gamma irradiation of starch. In Z. Sui \& X. Kong (eds.), Physical modifications of starch. Singapore: Springer, 63-96, https://doi. org/10.1007/978-981-13-0725-6_5.

14. Tariq Yasin, T., Nisar, M., Shafiq, M., Nho, Y. C. \& Ahmad, R. (2013). Influence of sepiolite and electron beam irradiation on the structural and physicochemical properties of polyethylene/starch nanocomposites. Polym. Compos., 43(3), 408-416, https://doi.org/10.1002/pc.22431.

15. Jiang, Z., Jian, Z., Yunhai, M. \& Jin, T. (2008). Surface photo-crosslinking of corn starch sheets. Carbohyd. Polym., 74(3), 405-410, https://doi. org/10.1016/j.carbpol.2008.03.006.

16. Annamalai, P. K. \& Raj, P. S. (2008). Biocomposite of cellulose reinforced starch: Improvement of properties by photo-induced crosslinking. Bioresource Tech., 99(18), 8803-8809, https://doi.org/10.1016/j. biortech.2008.04.045.

17. ASTM International (2003). ASTM Standard D638. Standard test method for tensile properties of plastics. Pennsylvania, USA: ASTM International.

18. Mohd Zain, A. H, Kahar, A. W. M. \& Hanafi, I. (2018). Solid-state photocross-linking of cassava starch: Improvement properties of thermoplastic starch. Polym. Bull., 75(8), 3341-3356, https://doi.org/10.1007/s00289017-2209-6.

19. Kahar, A. W. M., Ismail, H. \& Abdul Hamid, A. (2016). The correlation between crosslink density and thermal properties of high density polyethylene/natural rubber/thermoplastic tapioca starch blends prepared via dynamic vulcanisation approach. J. Therm. Anal. Calorim., 123(1), 301-308, https://doi.org/10.1007/s10973-015-4880-x.

20. Mohd Zain, A. H, Kahar, A. W. M. \& Hanafi, I. (2018). Biodegradation behaviour of thermoplastic starch: The roles of carboxylic acids on cassava starch. J. Polym. Environ., 26(2), 691-700, https://doi.org/10.1007/ s10924-017-0978-5. 
21. Mohd Zain, A. H., Kahar, A. W. M. \& Noriman, N. Z. (2016). Chemicalmechanical hydrolysis technique of modified thermoplastic starch for better mechanical performance. Procedia Chem., 19, 638-645, https://doi. org/10.1016/j.proche.2016.03.064.

22. Kahar, A. W. M., Sarifuddin, N. \& Ismail, H., 2017. Structural, thermal and physico-chemical properties of high density polyethylene/natural rubber/modified cassava starch blends. Ira. Polym. J., 26(2), 149-159. https://doi.org/10.1007/s13726-017-0507-3.

23. Salmah, H., Siti Rohana, A. \& Kamarudin, H. (2013). Effect maleic anhydride polypropylene on properties of calcium carbonate filled polypropylene/ethylene propylene diene terpolymer composites. Key Engineering Materials, 594-595, 770-774, https://doi.org/10.4028/www. scientific.net/KEM.594-595.770. 